\title{
Duplication of Aldolase and Esterase Loci in Cicer (Cicereae Alef.)
}

\author{
K. Kazan, I. Kusmenoglu, F. J. Muehlbauer, and N. F. Weeden
}

The genetic control of fructose bisphosphate aldolase (ALDO, EC 4.1.2.13) and esterase (EST, EC 3.1.1.2) isozymes in Cicer was studied by starch gel electrophoresis. Fixed heterozygote enzyme phenotypes were observed in homozygous lines for both Aldo-1, Aldo-2 and Est-4, Est-5. Crosses between the individuals carrying different alleles of the duplicated genes gave rise to asymmetrically staining bands for both enzyme systems. Subcellular localization studies demonstrated that the products of duplicated aldolase loci are present in the plastids, whereas duplicated esterase isozymes were found in the cytosolic compartment. Selfing and crossing experiments revealed that there are two nuclear genes encoding the plastid specific ALDO isozymes (A/do- 1 and Aldo-2). Similarly, EST-4 and EST-5 isozymes are specified by two nuclear genes (Est-4 and Est-5). No linkage was found between any of the duplicated genes and the other isozyme loci examined in this study. Taxonomic distribution of both duplications was examined in the electrophoretic survey of the related species. Present evidence suggests that these duplications are unique and probably occurred only in this monophyletic tribe, Cicereae, since no duplication was reported in the related genera. No evidence for mutations silencing any of the duplicated copies was detected in the genus. Although the mechanism for duplications is not known, evidence for translocations in Cicer and the existence of a similar linkage between ALDO and EST isozymes in related genera indicate that both duplications may have arisen simultaneously via duplication of a chromosomal segment carrying the ancestral state of the genes.

Gene duplications have been reported in a number of species of diploid plants (Ellstrand et al. 1983; Goldring et al. 1985; Gottlieb 1987; Odrzykoski and Gottlieb 1984; Pichersky and Gottlieb 1983; Soltis et al. 1987) and animals (Allendorf et al. 1975; Avise and Kitto 1973). Polyploid plants normally have duplicated isozymes as a consequence of genome duplication (Cai and Chinnappa 1989; Lumaret 1986; Martinez-Zapater and Oliver 1985). However, duplications of nuclear genes encoding the enzymes functioning in the glycolytic pathway have also been reported in a number of diploid plant species (Odrzykoski and Gottlieb 1984; Pichersky and Gottlieb 1983; Soltis et al. 1987). Maize, although usually considered to be a diploid plant, was found to have duplicated (McMillin and Scandalios 1981; Wendel et al. 1986) and even triplicated (Wendel et al. 1989) isozymes that have been observed for polyploid plant species. A great number of chromosomal segments are redundant in maize, as revealed by RFLP analysis (Helentjaris et al. 1988), suggest- ing that allopolyploidy may have been involved in the evolution of maize (Wendel et al. 1989).

Gene duplication is important in evolution because it appears to be one of the main mechanisms for the acquisition of new genes and consequently new metabolic capabilities (Gottlieb 1982). Accordingly, when a gene is duplicated, one of the two resultant genes either may become nonfunctional or may acquire a new function (Allendorf et al. 1984; Takahata 1982). A duplicated locus may be fixed in diploid populations by mutation pressure and random drift (Kimura and King 1979). Gene silencing may especially occur after polyploidization since many enzyme loci are the parts of a redundant gene pool in polyploid species (Wilson et al. 1983; Wolko and Weeden 1989). However, very little is known about how duplicated genes may diverge in regulation or in function.

More solid evidence for gene duplication requires a demonstration of similar amino acid sequences from both duplicates or a cytological demonstration of du- 
plicated chromosome material with their isozyme coding genes (Gottlieb 1982). However, electrophoretic studies can also reveal the multilocus nature of many enzyme systems, providing support for the gene duplication hypothesis (EIlstrand et al. 1983).

Aldolase (ALDO, EC 4.1.2.13) functioning in the glycolytic pathway catalyzes the reversible conversion of fructose diphosphate to glyceraldehyde 3 phosphate. Similar to other glycolytic pathway enzymes, two aldolase isozymes localized in plastolic and cytosolic compartments were found in higher plants (Bukowiecki and Anderson 1974). Fluorescent esterase (EST, EC 3.1.1.2) is associated with the biosynthesis of acetate. The presence of several esterase isozymes is known in plants (Doong and Kiang 1988; Weeden and Marx 1987). In this report we present evidence that duplication of the gene for plastid specific aldolase isozymes and one gene of the esterase isozymes has occurred during the evolution of Cicer $(\mathrm{Ci}$ cereae Alef.), consisting of diploid ( $2 n=$ 16), self-pollinated annual and perennial species. Based on crossability and fertility of hybrids in interspecific crosses, nine annual species of Cicer were divided into four crossability groups (Ladizinsky and Adler 1976). The first group includes three species-C. arietinum L., C. reticulatum Lad., and $C$. echinospermum Dav. Other species-C. bijugum Rech., C. pinnatifidum J., $C$. judaicum Boiss., and $C$. yamashitae Kitam.-are grouped in the second crossability group. The remaining two species-C. chorassanicum (Bge.) M. Pop. and C. cuneatum Hochst.-cannot be crossed with any other annual species and therefore they form the third and the fourth crossability groups, respectively.

\section{Materials and Methods}

\section{Plant Material}

We used true breeding diploid chickpea lines (Cicer arietinum) maintained by natural self-pollination to recognize the nature of the fixed heterozygote phenotype. An alternative allele for one of the duplicated loci (Aldo-I) was found in a wild species of chickpea, $C$. reticulatum. Segregation of aldolase isozymes was examined in the progeny of a cross (Family A) between $C$. arietinum (PI360177) and $C$. reticulatum (PI489777). We found polymorphism for the duplicated esterase locus in two $C$. arietinum accessions, and we examined segregation of this locus in the progeny of a cross (Family B) between two accessions, ILC 194 and FLIP 86-83. In addition, we determined the taxonomic distribution of duplications by an electrophoretic survey of all remaining annual species [C. reticulatum (PI489777, PI489778, PI510655), C. echinospermum (PI489776), C. bijugum (PI458550, PI458551, PI458552), C. pinnatifidum (PI458555, PI458556, PI510663), C. judaicum (PI458558, PI458559, PI504291), C. yamashitae (PI504550, PI510664), C. chorassanicum (PI458553), and C. cuneatum (PI458554)] and one perennial species [C. anatolicum Alef. (PI383626)] of Cicer obtained from the United States Department of Agriculture Regional Plant Introduction Station at Pullman, Washington.

\section{Enzyme Assays and Electrophoresis} We obtained enzyme extracts by grinding two or three leaflets of young seedlings in a $100 \mu$ l potassium phosphate, $\mathrm{pH} 7$, extraction buffer according to Soltis et al. (1983). For alcohol dehydrogenase (ADH, EC 1.1.1.1) we used extractions from roots soaked $18 \mathrm{~h}$ in water. To resolve alcohol dehydrogenase, aldolase (ALDO, EC 4.1.2.13), 6-phosphogluconate dehydrogenase (PGD, EC 1.1.1.44), and phosphoglucomutase (PGM, EC 2.7.5.1) we used a pH 6.1 histidine gel and electrode buffer (Cardy et al. 1980). To resolve aspartate aminotransferase (AAT, EC 2.6.1.1), aconitase (ACO, EC 4.2.13), glucose-1-phosphate transferase (GPT, EC 3.1.3.10), phosphogluco isomerase (PGI, EC 5.3.19), and seed protein (SPR) we used a triscitrate/lithium borate, $\mathrm{pH} 8.1$, gel system (Selander et al. 1971). To resolve fluorescent esterase (EST, EC 3.1.1.2) and $\beta$-Dgalactosidase (GAL, EC 3.2.1) we used a citrate/N-3-aminopropyl-morpholine gel system, pH 6.1 (Clayton and Tretiak 1972). Electrophoresis was carried out using a $10 \%$ starch gel for all the gel systems. We ran the gel for $4 \mathrm{~h}$ at a constant voltage of 310 for the assays conducted on the histidine gel system and at $45 \mathrm{~mA}$ for $4 \mathrm{~h}$ in a refrigerated cabinet for the other assays. The SPR was assayed with a naphthol blueblack solution ( 5 methanol: 5 water: 1 acetic acid). The remaining assays were identical to or slight modifications of those described by Soltis et al. (1983).

\section{Subcellular Location of Isozymes}

We determined subcellular location of the isozymes by comparing the electrophoretic patterns of pollen leachate, leaf extract, chloroplast, and mitochondrial preparations as described by Muehlbauer et al. (1989) and Weeden and Gottlieb (1980).

\section{Isozyme Nomenclature}

We designated the locus specifying the most anodally migrating isozyme as 1 , the next as 2, and so on. Similarly, we named the alleles at each locus according to the relative mobilities of their products. The most anodal allozyme at a given locus was assigned an "a"; the subsequent letters were used to indicate the slower migrating allozymes. We used the letters p, c, and $\mathrm{m}$ after the name of the locus to indicate the subcellular location of isozymes as plastid, cytosol, and mitochondria, respectively.

\section{Segregation and Linkage Analysis}

Parental lines maintained by self-pollination were selfed to demonstrate the homozygous nature of the plants. We made crosses between the plants differing for the alleles in one of the duplicated loci for aldolase (1aa2cc $\times 1 \mathrm{cc} 2 \mathrm{cc}$ ) and esterase (laa2aa $\times 1 \mathrm{aa} 2 \mathrm{bb}$ ), and we tested $\mathrm{F}_{2}$ progenies for deviation from expected Mendelian segregation ratios for a single locus. The LINKAGE-1 computer program (Suiter et al. 1983) was used for linkage analyses between Aldo-I and nine other isozyme loci (Aco-c, Aco-m, Pgd-c, Pgi-c, Pgm-p, Gpt$p$, Gpt-c, Adh-1, and Spr) segregating in Family $A$ and between Est-5 and Gal-1 segregating in Family $B$.

\section{Results}

\section{Fixed Heterozygosity}

The presence of true breeding individuals with multiple-banded electrophoretic patterns suggested the presence of duplicate genes coding for aldolase. A five-banded aldolase pattern was observed in $C$. arietinum, whereas only a very darkly stained region was found in $C$. reticulatum (PI489777). Both phenotypes did not segregate upon selfing, indicating that this is a fixed heterozygote phenotype (in which exist multiple-banded enzyme patterns of homozygous individuals that can normally be observed for heterozygous individuals) encoded by two distinct genes. However, segregation was obtained in crosses between the two species sharing one of the alleles for the duplicated locus but differing for the other (Figure 1). The enzyme genotypes of $C$. arietinum and $C$. reticulatum were designated as $1 \mathrm{aa} 2 \mathrm{cc}$ and $1 \mathrm{cc} 2 \mathrm{cc}$, respectively (Figure $3 a, c$ ). In $F_{1}$ hybrids, a five-banded pattern for aldolase was observed, indicating the tetrameric nature of the enzyme. The $F_{1}$ genotype was desig- 
$+$

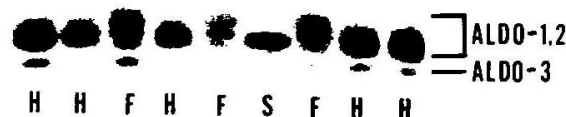

Figure 1. Segregation of isozyme phenotypes for Aldo- $I$ in an interspecific cross, $C$. arietinum $\times C$. re ticulatum (see text for details). $\mathrm{F}=$ fast, $\mathrm{S}=$ slow, $\mathrm{H}=$ heterozygous enzyme phenotype.

nated as 1ac2cc (Figure 3b). One- and three-banded phenotypes for the EST-4,5 region were found in two $C$. arietinum accessions used as parents in the crosses (ILC $194 \times$ FLIP 86-83) (Figure 2). The genotypes of the parents were designated as 4aa5aa for one-banded and 4aa5bb for three-banded phenotypes (Figure 3d,f). Selfing of the individuals with the threebanded pattern did not show segregation. The crosses between these two genotypes yielded a three-banded phenotype (4aa5ab) with two darkly stained bands and a fainter band at the third position (Figure 3e).

\section{Intergenic Interaction Producing Hybrid Isozymes}

Intergenic heterotetramers produced by the subunit association of the alleles at the duplicated Aldo loci were observed in all the species examined. Intergenic bands produced by random association of the polypeptides from duplicated genes indicate the structural similarity of the polypeptides from both genes. Since duplicated isozymes are expressed in the same genic interaction can easily occur between the isozymes, producing multiple bands. No distinguishable intergenic band was observed in $C$. reticulatum because the alleles at both loci have the same electrophoretic mobility for duplicated isozymes. subcellular compartment (plastid), inter-
$+$

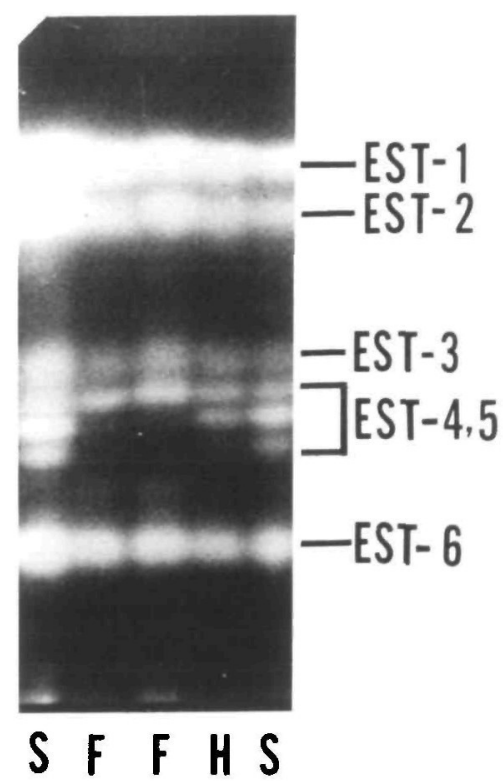

Figure 2. Segregation of isozyme phenotypes for Est-5 in an intraspecific cross, ILC $194 \times$ FLIP 86-83 (see text for details). $\mathrm{F}=$ fast, $\mathrm{S}=$ slow, $\mathrm{H}=$ heterozygous enzyme phenotype.

No intergenic interaction was observed between cytosolic aldolase isozyme (Aldo3 ) and the duplicated plastid specific isozymes (Aldo-I and Aldo-2).

Similarly, a three-banded enzyme phenotype was produced by subunit association of the genes encoding EST-4 and EST-5 isozymes. A one-banded phenotype observed in one of the parents was probably due to the fact that the products of both loci overlap on the gel. We found all esterase isozymes exclusively localized in the cytosol. Existence of both isozymes in the same subcellular compartment allows products of the duplicated loci to combine and produce a fixed heterozygote phenotype. No intergenic interaction between any other esterase loci products was observed. This suggests that these loci have diverged.

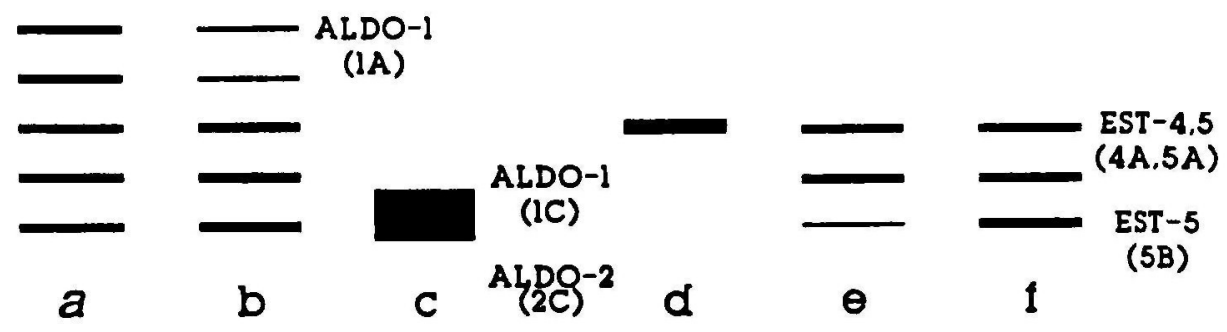

Figure 3. Diagram of the electrophoretic phenotypes for aldolase: (a) 1aa2cc (C. arietinum, PI360177); (b) lac2cc heterozygous; (c) Icc2cc ( $C$. reticulatum, P1489777) parental. Also for esterase isozymes: (d) 4aa5aa ( $C$. arietinum, ILC 194); (e) 4aa5ab heterozygous; (f) 4aa5bb (C. arietinum, FLIP 86-83) parental. Only duplicated isozymes are shown.

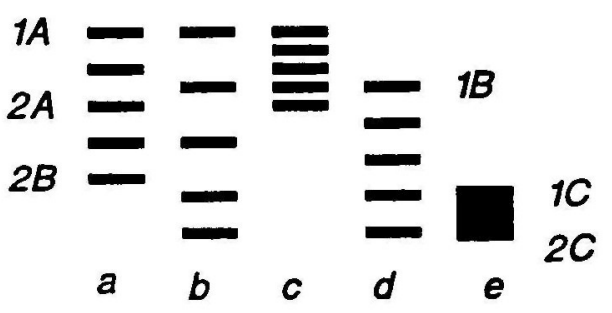

Figure 4. Diagram of aldolase isozymes in Cicer species: (a) laa2bb (C. chorassanicum); (b) 1aa2cc [C. arietinum, C. reticulatum (PI489778, PI510655), C. echinospermum, $C$. bijugum, C. pinnatifidum, $C$. judaicum] (c) laa2aa (C. yamashitae, C. anatolicum); (d) $1 \mathrm{bb} 2 \mathrm{cc}$ (C. cuneatum); (e) 1cc2cc [C. reticulatum (PI489777)].

Gene Dosage Effect in Heterozygotes

Asymmetrical banding intensities were observed for heterozygous individuals for both duplicated esterase and aldolase loci (Figures 1 and 2). In the duplicated esterase locus the $a$ allele encodes a fast allozyme and the $b$ allele encodes a slow allozyme. Accordingly, the fast band will be more intense in an individual with $4 \mathrm{aa} 5 \mathrm{ab}$ genotype because of the dosage effect of $a$. Similar observations were made for heterozygous individuals ( $1 \mathrm{ac} 2 \mathrm{cc}$ ) at the duplicated aldolase locus. Due to the dosage effect of $c$, three relatively darker staining bands with a relatively lighter staining portion were observed in the heterozygote. This situation was proposed as evidence for gene duplication (Cai and Chinnappa 1989; Martinez-Zapater and Oliver 1985; Weeden et al. 1989).

\section{Taxonomic Distribution of Gene Duplications}

The alleles at the duplicated aldolase loci are illustrated graphically in Figure 4. No variation was found within each species except $C$. reticulatum, which showed one(PI489777) and five-banded (PI489778 and PI510655) phenotypes for the different alleles of the duplicated genes. Different alleles were fixed for most of the species examined. Three alleles were detected for both Aldo- 1 ( $1 \mathrm{a}, 1 \mathrm{~b}, 1 \mathrm{c})$ and Aldo-2 (2a, 2b, $2 c$ ) in a survey of all annual and one perennial ( $C$. anatolicum) species of Cicer. Species in the first two crossability groups, except $C$. reticulatum (PI489777), shared the same alleles for both Aldo-l and Aldo2 . Similarly, $C$. cuneatum and $C$. reticulatum had the same allele for Aldo-2, but they differed from the remaining species for the Aldo- 1 allele. Two other wild species, $C$. yamashitae and $C$. anatolicum, differed from the other species by having the same allele for Aldo-2.

Two alleles were found for the duplicated Est-5 in three species of the genus, 
Table 1. Segregation of duplicated isozyme phenotypes in $F_{2}$ progenies of an interspeciflc hybrid [Famlly A: $C$. arietinum (PI360177) $\times C$. reficulatum (PI489777)], and an intraspecific hybrid, $C$. arietinum (Family B: ILC 194 × FLIP 86-83), and single locus goodness of fit to a 1:2:1 expected genetic ratio

\begin{tabular}{|c|c|c|c|c|c|c|}
\hline \multirow[b]{2}{*}{ Family } & \multirow[b]{2}{*}{ Locus } & \multicolumn{3}{|c|}{$\begin{array}{l}\text { No. of plants with } \\
\text { designated phenotype }\end{array}$} & \multirow[b]{2}{*}{$x^{2}$} & \multirow[b]{2}{*}{$P$} \\
\hline & & Fast & $\begin{array}{l}\text { Hetero- } \\
\text { zygotes }\end{array}$ & Slow & & \\
\hline$A$ & Aldo-I $(\mathrm{p})^{*}$ & 16 & 28 & 15 & 0.19 & .91 \\
\hline B & Est-5 & 38 & 89 & 33 & 2.33 & .31 \\
\hline
\end{tabular}

${ }^{a} \mathbf{p}=$ plastid.

C. arietinum (5a and $5 \mathrm{~b}), C$. reticulatum $(5 \mathrm{a})$, and $C$. echinospermum (5a). Complex banding patterns for esterase isozymes in the remaining species prevented further evaluation of this duplication.

\section{Genetic Control of ALDO and EST Phenotypes in Cicer}

Self-pollination of individuals within the parental lines yielded progeny with the same aldolase phenotypes as the parents, indicating the homozygosity of the parents. However, the cross between them produced $F_{1}$ progeny that consisted of both parental and heterotetrameric enzymes. This is due to the fact that both parents have the same allele for the less anodal plastid isozyme (ALDO-2); however, they differ by having different alleles for the more anodal (ALDO-1) plastid specific isozymes. Three progeny classes occurred in the $F_{2}$, five- and one-banded parental phenotypes and the five-banded $F_{l}$ phenotype. The number of individuals in the progeny classes approximated a 1:2:1 ratio expected for codominant alleles segregating at a single locus (Table 1).

Six zones of activity for esterase were observed. The two most anodal isozymes are monomeric and under the control of two linked loci (Kusmenoglu I, Muehlbauer FJ, and Kazan $\mathrm{K}$, in preparation).
The genetic control of the third and sixth most anodal isozymes are not known. The present study revealed that zone 4 and zone 5 isozymes are controlled by a duplicated locus. Variation was found for only zone 5 (EST-5) isozymes in the crossable parents. Crosses between the parental genotypes differing by the alleles for zone 5 isozymes yielded both parental and heterozygote phenotypes in the $F_{2}$, and segregation fit the expected 1:2:1 ratio for a single locus (Table 1).

\section{Linkage Tests}

Testing the linkage between duplicated aldolase loci was not possible because only one locus showed variation in the parents. Testing the same linkage in some other Cicer species carrying different alleles for both Aldo-1 and Aldo-2 was not possible due to the crossability barriers.

Tests of linkage between Aldo- 1 and nine isozyme loci (Family A) are presented in Table 2. Aldo-1 segregated independently from the other loci tested. All other isozyme loci exhibited codominant expression of allozymes and gave 1:2:1 segregation ratios in the $F_{2}$.

Testing the linkage between duplicated esterase loci was also not possible due to lack of polymorphism for both duplicates in the parental genotypes. Although the

Table 2. Jolnt segregation between Aldo-1 and nine other Isozyme loci in Family A (PI360177 $\times$ PI489777) and between Est-5 and Gal.I in Family B (ILC $194 \times$ FLIP 86-83) and tests for llnkage

No. of $F_{2}$ plants with designated phenotypes ${ }^{a}$

\begin{tabular}{|c|c|c|c|c|c|c|c|c|c|c|c|c|c|}
\hline \multirow[b]{2}{*}{ Family } & \multirow[b]{2}{*}{ Locus $^{b}$} & & \multirow[b]{2}{*}{$x^{2}$} & \multirow[b]{2}{*}{$r^{c}$} & \multirow[b]{2}{*}{$P$} \\
\hline & & $\mathbf{F F}$ & FH & FS & $\mathrm{HF}$ & $\mathrm{HH}$ & HS & $\mathrm{SF}$ & SH & SS & & & \\
\hline A & $\begin{array}{l}\text { Aco-c } \\
\text { Aco-m } \\
\text { Pgd-c } \\
\text { Pgi-c } \\
\text { Pgm-p } \\
\text { Gpt-p } \\
\text { Gpt-c } \\
\text { Adh-I } \\
\text { Spr }\end{array}$ & $\begin{array}{l}5 \\
4 \\
0 \\
5 \\
3 \\
5 \\
3 \\
5 \\
4\end{array}$ & $\begin{array}{r}8 \\
7 \\
12 \\
11 \\
5 \\
6 \\
11 \\
7 \\
11\end{array}$ & $\begin{array}{l}2 \\
1 \\
6 \\
3 \\
2 \\
5 \\
1 \\
5 \\
2\end{array}$ & $\begin{array}{r}8 \\
7 \\
11 \\
7 \\
6 \\
8 \\
11 \\
9 \\
10\end{array}$ & $\begin{array}{r}13 \\
16 \\
8 \\
13 \\
5 \\
13 \\
9 \\
9 \\
13\end{array}$ & $\begin{array}{r}8 \\
9 \\
7 \\
9 \\
11 \\
7 \\
7 \\
7 \\
10\end{array}$ & $\begin{array}{l}3 \\
5 \\
5 \\
4 \\
7 \\
3 \\
2 \\
2 \\
2\end{array}$ & $\begin{array}{r}6 \\
4 \\
7 \\
3 \\
7 \\
8 \\
7 \\
11 \\
3\end{array}$ & $\begin{array}{l}\mathbf{5} \\
\mathbf{5} \\
\mathbf{2} \\
\mathbf{3} \\
2 \\
\mathbf{3} \\
7 \\
\mathbf{3} \\
\mathbf{3}\end{array}$ & $\begin{array}{r}2.05 \\
4.28 \\
11.50 \\
2.94 \\
4.63 \\
1.19 \\
10.79 \\
4.82 \\
3.89\end{array}$ & $\begin{array}{l}42 \\
44 \\
39 \\
48 \\
41 \\
49 \\
41 \\
49 \\
42\end{array}$ & $\begin{array}{l}.73 \\
.37 \\
.02 \\
.57 \\
.33 \\
.88 \\
.03 \\
.31 \\
.42\end{array}$ \\
\hline B & Gal-1 & 10 & 20 & 8 & 20 & 46 & 23 & 13 & 15 & 5 & 4.06 & 45 & .03 \\
\hline
\end{tabular}

o $\mathrm{F}=$ homozygous fast; $\mathrm{S}=$ homozygous slow; $\mathrm{H}=$ heterozygous.

${ }^{\circ} \mathrm{c}=$ cytosol; $\mathbf{m}=$ mitochondria; $\mathrm{p}=$ plastid.

- Recombination fraction.

linkage between Gal-1 and Est-5 (Family B) was tested, no linkage was found (Table 2).

\section{Discussion}

Evidence was presented for duplication of two enzyme loci in Cicer. The presence of a fixed heterozygote enzyme phenotype, intergenic interaction producing heteromeric isozymes, and the presence of the duplicated isozymes in the same subcellular compartments all indicated the duplicated states of the genes. Additionally, we have evidence to suggest a possible segment duplication giving rise to the duplicated isozymes in this genus. Although relatively rare, duplication of a segment of a chromosome carrying genes encoding cytosolic and mitochondrial malate dehydrogenase isozymes has been reported in maize (McMillin and Scandalios 1980). Cytosolic $M d h-1$ and $M d h-2$ were located on different maize chromosomes, and both $M d h-l$ and $M d h-2$ were found to be linked to two aminopeptidase loci (Amp-1 and Amp-2). This suggested that the region including $M d h-c$ and $A m p$ may have been duplicated (McMillin and Scandalios 1981). Although we do not have direct evidence suggesting a linkage between duplicated aldolase and esterase loci in Cicer, a similar linkage between these two loci was reported in Pisum (Weeden and Marx 1987). The same linkage situation may exist in Cicerbecause the presence of several conserved linkage groups consisting of homologous genes among the members of Viceae has been demonstrated (Muehlbauer et al. 1989; Weeden et al. 1988). We are currently attempting to demonstrate a similar linkage group in Cicer. The presence of a linkage between Aldo and $S k d h$ is also known in Pisum (Weeden and Marx 1987). In contrast to Pisum and Lens, for which only one SKDH isozyme was reported, two SKDH isozymes were resolved in Cicer. The duplication of Aldo and Est loci and putative duplication of a $S k d h$ locus suggests the possible duplication of a chromosome segment carrying the ancestral state of the duplicated genes. No polymorphism was found within each crossability group of Cicer for Skdh to test the possibility of linkage among these three loci (Kazan K, unpublished).

Gottlieb (1982) proposed a mechanism by which gene duplication may occur. Accordingly, most of the duplications with unlinked copies may have arisen from plants that were heterozygous for overlap- 
ping reciprocal translocations. Duplicate genes were found unlinked for most of the instances, suggesting that they do not usually originate by unequal crossing over. Gene duplications fitting the proposed mode of origin were observed for a number of isozyme gene duplications (Pichersky and Gottlieb 1983; Tanksley 1984; Tanksley and Kuehn 1985). As apparent from the model, chromosomal rearrangements are precursors for the gene and segment duplications. Although several chromosomal rearrangements have also been identified in Cicer (Ladizinsky and Adler 1976), whether these rearrangements gave rise to the duplicated genes remains unknown.

Allendorf (1978) discussed the possible fate of duplicated genes. The main reason for conservation of duplicated loci would be selective advantage of the individuals with the gene duplications. Since the number of isozymes is increased in fixed heterozygote individuals, larger amounts of enzyme with slightly different biochemical properties may be produced. The difference between the individuals with and without gene duplication might be very distinct in nature, especially under adverse conditions. This might be true for the aldolase gene duplication, although we do not know the biochemical properties of additional isozymes developed from gene duplication. However, the esterase duplication will probably be silenced because duplicated isozymes are already a part of a redundant enzyme system.

Gene duplications have also been used extensively in plant systematics to clarify the evolutionary relationships among taxa (Odrzykoski and Gottlieb 1984; Soltis et al. 1987) due to the fact that they are very rare events and probably occur only once in the evolution of a genus. Similarly, loss of duplication in some species within a genus suggests the phylogenetic similarity among them. The gene encoding the cytosolic PGI, Pgi-c, was found duplicated within the Leguminosae (Weeden et al. 1989). The distribution of this gene duplication among the members of the family led to the conclusion that the duplication had occurred in the lineage leading to Phaseolus after its divergence from that leading to Pisum and Lens. Similarly, restriction of present duplications to Cicer, a monophyletic genera in the Cicereae, suggests that the duplication probably occurred after the divergence of the tribe from other related taxa.

The distribution of a gene duplication among the related taxa may also reveal some information about the age of a duplication. For example, the present duplications involving ALDO and EST cannot be considered ancient because no duplication of these two loci has been reported in related genera. This suggests that the duplicated enzyme loci are still at the early stages of differentiation since they produce polypeptides that are structurally and metabolically similar, allowing the formation of heteropolymers.

Genetic and biochemical evidence suggests that the duplication of plastid specific aldolase and an esterase locus occurred by a process of a gene and possibly a segment duplication. However, biochemical evidence of structural and sequence similarity for the genes or their products is not yet available. Currently, the ancestral state of the genes is also not known.

\section{References}

Allendorf FW, 1978. Protein polymorphism and the rate of loss of duplicate gene expression. Nature 272 : 76-78.

Allendorf FW, Stahl G, and Ryman N, 1984. Silencing of duplicate genes: a null allele polymorphism for lactate dehydrogenase in brown trout (Salmo trutta). Mol Biol Evol 3:238-248.

Allendorf FW, Utter FM, and May BP, 1975. Gene duplication within the family Salmonidae: II. Detection and determination of the genetic control of duplicate loci through inheritance studies and the examination of populations. In: Isozymes IV (Markert CL, ed). New York: Academic Press; 415-432.

Avise JC and Kitto GB, 1973. Phosphoglucose isomerase gene duplication in the bony fishes: an evolutionary history. Biochem Genet 8:113-132.

Bukowiecki AC and Anderson LE, 1974. Multiple forms of aldolase and triose phosphate isomerase in diverse plant species. Plt Sci Lett 3:381-386.

Cai $Q$ and Chinnappa CC, 1989. Gene duplication of isozymes in the tetraploid of Stellaria longipes (Caryophylaceae). J Hered 80:112-117.

Cardy BJ, Stuber CW, and Goodman MM, 1980. Techniques for starch gel electrophoresis of enzymes from maize (Zea mays L.) (Mimeo Series No 1317). Raleigh NC: North Carolina State University Dept Stat.

Clayton JW and Tretiak DN, 1972. Amine-citrate buffers for $\mathrm{pH}$ control in starch gel electrophoresis. J Fish Res Bd Can 29:1169-1172.

Doong JYH and Kiang YT, 1988. Inheritance study on a soybean fluorescent esterase. J Hered 79:399-400.

Ellstrand NC, Lee JM, and Foster KW, 1983. Alcohol dehydrogenase isozymes in grain sorghum (Sorghum bicolor): evidence for a gene duplication. Biochem Genet 21:147-155.

Goldring A, Zamir D, and Degani C, 1985. Duplicated phosphoglucose isomerase genes in avocado. Theor Appl Genet 71:491-494.

Gottlieb LD, 1982. Conservation and duplication of isozymes in plants. Science 216:373-380.

Gottlieb LD, 1987. Phosphoglucomutase and isocitrate dehydrogenase gene duplications in Layia (Compos. itae). Am J Bot 74:9-15.

Helentjaris T, Weber DF, and Wright S, 1988. Duplicate sequences in maize and identification of their genomic locations through restriction fragment length polymorphisms. Genetics 118:353-363.

Kimura $M$ and King JL, 1979. Fixation of deleterious allele at one of two duplicate loci by mutation pressure and random drift. Proc Natl Acad Sci USA 76:28582861 .

Ladizinsky G and Adler A, 1976. Genetic relationships among annual species of Cicer L. Theor Appl Genet 48: 197-203.

Lumaret $R, 1986$. Doubled duplication of the structural gene for cytosolic phosphoglucose isomerase in the Dactylis glomerata L. polyploid complex. Mol Biol Evol 6:499-521.

Martinez-Zapater JM and Oliver JL, 1985. Isozyme gene duplication in diploid and tetraploid potatoes. Theor Appl Genet 70:172-177.

McMillin DE and Scandalios JG, 1981. Genetic analysis of the duplicated genes coding for mitochondrial malate dehydrogenase in Zea mays. possible origin of $M d h$ genes by chromosome segment duplication. Mol Gen Genet 182:211-221.

Muehlbauer FJ, Weeden NF, and Hoffman DL, 1989. Inheritance and linkage relationships of morphological and isozyme loci in lentil (Lens Miller). J Hered 80:293-303.

Odrzykoski IJ and Gottlieb LD, 1984. Duplication of genes coding 6-phosphogluconate dehydrogenase Clarkia (Onagraceae) and their phylogenetic implications. Syst Bot 9:479-489.

Pichersky E and Gottlieb LD, 1983. Evidence for duplication of the structural genes coding plastid and cytosolic isozymes of triose phosphate isomerase in diploid species of Clarkia. Genetics 105:421-436.

Selander RK, Smith MH, Yang SY, Johnson WE, and Gentry JB, 1971. Biochemical polymorphism and systematics in the genus Peremyscus. I. Variation in the old-field mouse (Peromyscus polionotus) (Publ 7103). Austin: University of Texas; 49-90.

Soltis DE, Haufler CH, Darrow DC, and Gastony GJ, 1983. Starch gel electrophoresis of ferns: a compilation of grinding buffers and staining schedules. Am Fern J 73:9-27.

Soltis PS, Soltis DE, and Gottlieb LD, 1987. Phosphoglucomutase gene duplications in Clarkia (Onagraceae) and their phylogenetic implications. Evolution 41:667-671.

Suiter KA, Wendel JF, and Case JS, 1983. LINKAGE-1: a PASCAL computer program for the detection and analysis of genetic linkage. J Hered 74:203-204.

Takahata N, 1982. The disappearance of duplicate gene expression. In: Molecular evolution, protein polymorphism and the neutral theory (Kimura $M$, ed). Tokyo: Japan Scientific Societies Press; 169-190.

Tanksley SD, 1984. Linkage relationships and chromosomal locations of enzyme coding genes in pepper, Capsicum annuum. Chromosoma 89:352-360.

Tanksley SD and Kuehn GD, 1985. Genetics, subcellular localization, and molecular characterization of 6-phosphogluconate dehydrogenase isozymes in tomato. Biochem Genet 23:441-454.

Weeden NF, Doyle JJ, and Lavin M, 1989. Distribution and evolution of a glucosephosphate isomerase duplication in the Leguminosae. Evolution 43:1637-1651.

Weeden NF and Gottlieb LD, 1980. The genetics of chloroplast enzymes. J Hered 71:392-396.

Weeden NF and Marx GA, 1987. Further genetic analysis and linkage relationships of isozyme loci in the pea: confirmation of the diploid nature of the genome. J Hered 78:153-159.

Weeden NF, Zamir D, and Tadmor Y, 1988. Application of isozyme analysis in pulse crops. In: World crops: cool season food legumes (Summerfield RJ, ed). Dordrecht, the Netherlands: Kluwer Academic Publishers; 979-987.

Wendel JF, Stuber CW, Edwards MD, and Goodman 
MM, 1986. Duplicated chromosome segments in Zea mays $L$.: further evidence for hexokinase isozymes. Theor Appl Genet 72:178-185.

Wendel JF, Stuber CW, Goodman MM, and Beckett JB, 1989. Duplicated plastid and triplicated cytosolic iso- zymes of triosephosphate isomerase in maize (Zea mays L.). J Hered 80:218-282.

Wilson HD, Barber SC, and Walters T, 1983. Loss of duplicate gene expression in tetraploid Chenopodium. Biochem Syst Ecol 11:7-13.
Wolko B and Weeden NF, 1989. Isozyme number in five lupin species suggests a tetraploid genome with considerable silencing of duplicate loci. In: Proceedings of the 5th International Lupin Conference PWRIL, Poznan, Poland (Twardowski T, ed); 516-520. 